\title{
Analysis of Dynamic Characteristics of Portal Frame with Variable Section
}

\author{
Jianing HAO \\ Sichuan College of Architecture Technology, Deyang, Sichuan, 618000, China \\ xd1988719@163.com ${ }^{1}$
}

\begin{abstract}
Combined with a portal frame design, by the use of finite element software ANSYS, the finite element model of single specimens of portal rigid frame and the overall portal rigid frame building are established. portal rigid frame's beam and column is variable cross section. Through the modal analysis, comparative analysis of the frequency and vibration type of the radiolabeling specimens and finite element model of the whole, for the further development of variable cross-section portal rigid frame of earthquake and wind vibration analysis lay the foundation.
\end{abstract}

\section{Introduction}

Portal frame structure has many advantages, such as large space, variable structure, simple structure, beautiful shape, light weight, high safety performance, good seismic performance, energy saving and environmental protection, removal and relocation[1-2]. At present, there are many factory buildings with portal frame structure. Variable cross-section portal rigid frame can enable cross section layout and effect to the gate type steel frame internal force corresponding to [3], and give full play to the steel performance, to achieve the purpose of saving steel.

\section{Finite Element Model}

Portal Frame Parameters. The span of plant is $36 \mathrm{~m}, 12 \mathrm{~m}$ on the cornice, under the eaves height is $10 \mathrm{~m}$, double slope roof, the slope is $1 / 9$. About $9 \mathrm{~m}$, a total of 10 vertical trusses, a total length of $90 \mathrm{~m}$. Beam flange size is $350 \mathrm{~mm} \times 18 \mathrm{~mm}$, web size is $1350 \mathrm{~mm} \sim 850 \mathrm{~mm} \times 12 \mathrm{~mm}$, column flange size is $350 \mathrm{~mm} \times 20 \mathrm{~mm}$, web size is $400 \mathrm{~mm} \sim 1350 \mathrm{~mm} \times 12 \mathrm{~mm}$. Section of purlin size for H300mm x $300 \mathrm{~mm} \times 12 \mathrm{~mm} \times 20 \mathrm{~mm}$, wall frame beam section for $H 300 \mathrm{~mm} \times 300 \mathrm{~mm} \times 12 \mathrm{~mm} \times 20 \mathrm{~mm}$, supporting with the diameter of $21 \mathrm{~mm}$ bar, supporting the initial strain value of 0.003 . Wind resistant column using box shaped section beam. Steel Q235 steel, the elastic modulus of steel is $2.1 \mathrm{x} 1011$, the density is $7850 \mathrm{~kg} / \mathrm{m} 3$, Poisson's ratio is 0.3 .

Finite Element Model. Using ANSYS software to establish the finite element model of portal frame, due to the portal frame model of beam to column for variable cross-section, with variable section beam beam44 to simulate. Respectively, the door type rigid frame

*Corresponding author:xd1988719@163.com 
beam column, divided into 6 sections, each section is defined by a constant cross section at both ends to generate variable section beam column. Structure finite element model as shown in Figure 1, the three directions of translation is binding in the heel, the release of three rotational degrees of freedom.

When establishing the overall model, the rin roof, gable column, girder wall and a horizontal supporting role, rigid frame at both ends is considered, and the frame ends, two middle truss and column are provided between the support. In the modeling process is first established the variable section beam column, purlin is generated on the basis of this, wall frame, gable column and column support, thus forming 1 / 4 model, followed by a YZ plane mirror and on the XY plane mirror to generate the overall portal rigid frame model, such as shown in Figure 2.

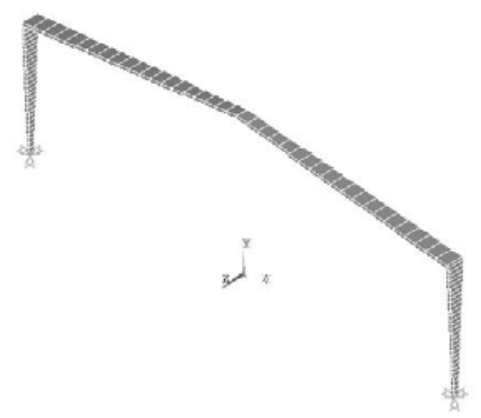

Fig 1 Rigid frame finite element model of single beam gantry

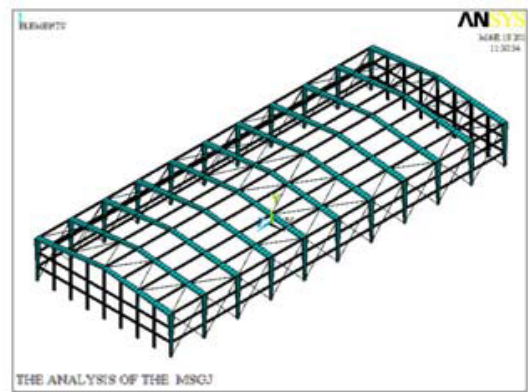

Fig 2 Finite element model of the whole portal frame

\section{Modal Analysis}

Calculation Assumption. The use of finite element software ANSYS, usually to portal rigid frame structure system to make some assumptions, the calculation assumed in the following several aspects[4-5],

1) Portal rigid frame beam and steel column, purlins and wall beam and frame beams and columns are connected by rigid connection, the column is hinged and support and the main body frame between connection also articulated form.

2) It is assumed that the constitutive model of all steel structural members is an ideal elastic material, and the plastic deformation of the member is neglected, and only the linear elastic calculation is carried out.

3) Beams, columns, and support units are selected frame element simulation, single truss model is a two-dimensional plane model. The whole model is a $3 \mathrm{D}$ model.

4) The skin effect of the roof profiled sheet is neglected.

Basic Principles. Free vibration equations is as follows,

$$
\left[\begin{array}{ll}
M & ]
\end{array} \dot{v}(t)\right\}+[K]\{\dot{v}(t)\}=0
$$

This system will do simple harmonic motion, the expressions of displacement is as follows,

$$
v(t)=A \sin (\omega t+\theta)
$$

Equation (3) is a problem for solving eigenvalue problems, the characteristic value 
$\omega^{2}$ is the square of the free vibration frequency, and the corresponding eigenvalue vector $\hat{v}$ represents the vibration mode of the vibration system.

The value of the matrix determinant is equal to 0 , then the frequency and vibration mode of the matrix can be obtained.

$$
\left|[K]-\omega^{2}[M]\right|=0
$$

Calculation Results. Using subspace iteration method, the influence of the first 20 modes of vibration mode is considered, and the extended mode is also taken as the 20 order. As can be seen from table 1, the fundamental frequency of the two fundamental frequency difference is relatively large, which is due to the spatial effect of the whole model. The frequency of the $2 \sim 4$ is very close.

Table 1 The First 4 Order Frequency (Hz) Of The Model

\begin{tabular}{ccccc}
\hline $\begin{array}{c}\text { Mode order } \\
\text { number }\end{array}$ & 1 & 2 & 3 & 4 \\
\hline $\begin{array}{c}\text { Single frame } \\
\text { model }\end{array}$ & 1.156 & 2.54 & 6.562 & 12.480 \\
$\begin{array}{c}\text { Integral model } \\
\text { nat }\end{array}$ & 1.950 & 2.650 & 6.616 & 12.517 \\
\hline
\end{tabular}

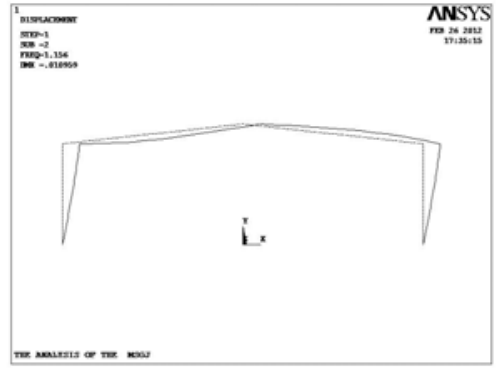

(a) First order mode

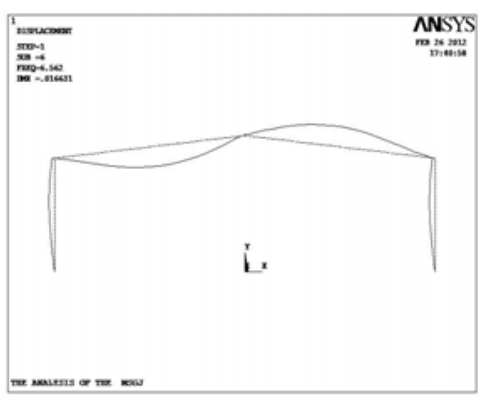

(c) Third order mode

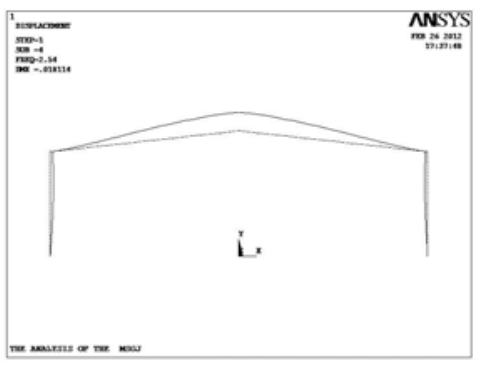

(b) Second order mode

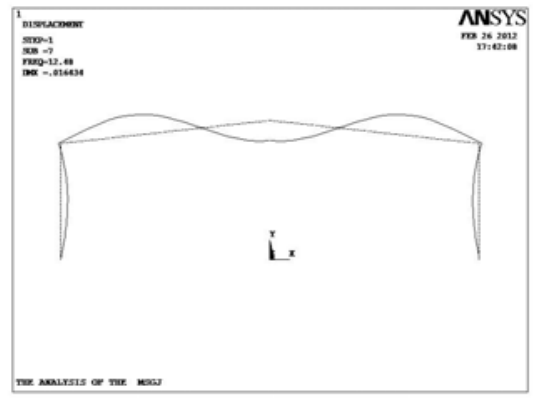

(d) Fourth order mode

Figure 3 single frame model with 4 modes of map

The first 4 order modes of the whole model are shown in Figure 4. From figure first it can be seen that the 4 order mode is vibration about the left and right. From the beginning of the second stage, if the observation from the side, the beam type vibration phenomenon, that is, the second order mode has 1.5 wave, 2.5 wave, third wave, gradually increasing to 
meet the $\cos n \theta$ vibration mode of beam type.

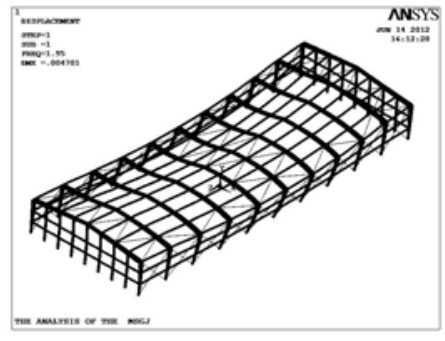

(a) First order mode

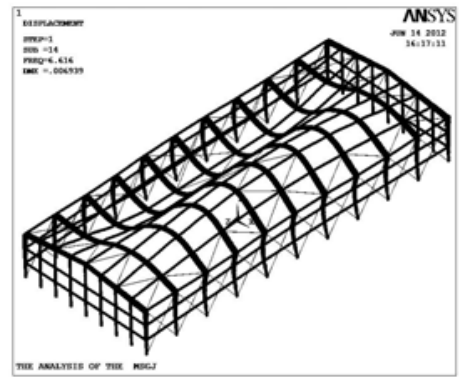

(c) Third order mode

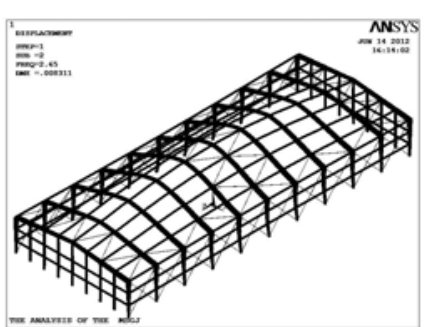

(b) Second order mode

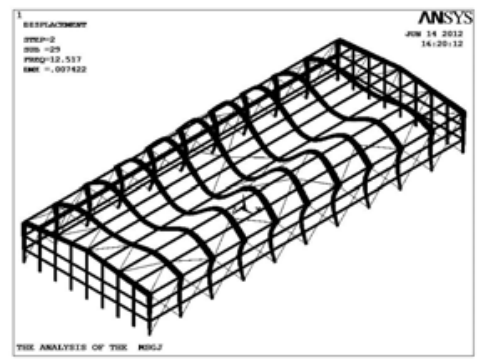

(d) Fourth order mode

Fig. 4 The first 4 order vibration mode of the whole model

\section{Conclusions}

ANSYS software was used to build the single frame and the overall portal frame finite element model, the following conclusions are obtained through modal analysis.

1. Single pin and overall model of vibration are basically the same, the first order is vibration about the left and right., the vibrations of the beam after the order of a vibration form. The vibration mode of the beam type vibration of the upper and lower is presented at the the later order.

2. The overall model of fundamental frequency is greater than the single pin model, which is due to the role of the whole space, the overall model of side shift greater stiffness than single pin model caused by. While the overall model stiffness increases smaller, so the vibration frequency close to single frame model.

\section{References}

1. Ting Yuan, A large slope and light portal frame static and dynamic performance analysis of [D]. Wuhan University of Technology, 2011

2. Guohua Qiu, Domestic and international light steel structure application development survey [J]. construction technology, 1999, 28 (8), 3-5.

3. Guiguo Zhang. Study of portal frame with variable cross section position of the [J]. coal preparation technology, 2006, Vol.10 (3), 43-45.

4. Lifeng Zhang. Finite element analysis of variable cross-section portal rigid frame [D]. Xi'an University of technology, 2006

5. Zhiqing Wei, Xiaoguang Zhao. Finite element analysis of portal frame light steel structure [J]. foreign building materials science and technology, 2008,29 (6), 132-134. 